\title{
DESENVOLVIMENTO DE SORVETE A BASE DE LEITE SABORIZADO COM POLPA DA ROMÃ 'WONDERFUL'
}

\author{
COELHO, Bruno Emanuel Souza ${ }^{1}$ \\ SOUSA, Karla dos Santos Melo de ${ }^{2}$ \\ SILVA, Cleciene Nunes $\mathrm{da}^{3}$ \\ SANTANA, Marisa da Silva ${ }^{4}$ \\ MUDO, Laiane Eugenia Delmondes ${ }^{5}$ \\ ALVES, David Castro ${ }^{6}$
}

\begin{abstract}
RESUMO: O interesse por produtos alimentícios saudáveis, nutritivos tem aumentado mundialmente, o que resulta em diversos estudos na área de produtos lácteos. , O objetivo do presente trabalho foi desenvolver uma formulação de sorvete a base de leite saborizado com polpa de romã 'Wonderful', bem como avaliar suas características físicoquímicas. O sorvete foi elaborado seguindo as etapas de: recepção, mistura de ingredientes, pasteurização, maturação, adição de sabor e congelamento. O produto final foi caracterizado quanto aos parâmetros de: $\mathrm{pH}$, acidez titulável, sólidos totais, umidade, açúcares redutores, açúcares não redutores, açúcares totais, gordura, cinzas, vitamina $\mathrm{C}$, zinco, magnésio, cobre chumbo, manganês e ferro. Os resultados mostraram que o sorvete encontra-se de acordo com a legislação brasileira vigente quanto ao teor de sólidos totais, apresenta alto valor mineral no que se refere ao zinco e magnésio, e elevado teor de açúcares. O sorvete apresenta-se como ideal para o consumidor que em sua alimentação possua restrição de gorduras. Não foram detectados teores de cobre, chumbo, manganês e ferro nas amostras. A pesquisa de produtos lácteos à base de frutos contribui para a diversificação no mercado, atendendo as necessidades dos consumidores, que buscam por novos sabores, uma alimentação saudável e alternativa.
\end{abstract}

Palavras-Chave: Punica granatum L.. Gelados comestíveis. Produtos lácteos. Bromatologia.

\section{DEVELOPMENT OF ICE CREAM A MILK BASED WITH FLAVORED OF POMEGRANATE PULP CV 'WONDERFUL'}

\begin{abstract}
SUMMARY: The interest in healthy, nutritious food products has increased worldwide, resulting in several studies in the field of dairy products. , The objective of the present work was to develop a formulation of ice cream based on milk flavored with 'Wonderful' pomegranate pulp, as well as to evaluate its physicochemical characteristics. The ice cream was prepared following the steps of: receiving, mixing ingredients, pasteurizing, ripening, adding flavor and freezing. The final product was characterized as $\mathrm{pH}$, titratable acidity, total solids, moisture, reducing sugars, nonreducing sugars, total sugars, fat, ashes, vitamin $\mathrm{C}$, zinc, magnesium, lead copper, manganese and iron. The results showed that the ice cream is in accordance with the Brazilian legislation in force regarding the total solids content, presents high mineral value in relation to zinc and magnesium, and high sugar content. The ice cream presents itself as ideal for the consumer that in its diet has fat restriction. No copper, lead, manganese and iron contents were detected in the samples. The research of dairy products based on fruits contributes to the diversification in the market, meeting the needs of consumers, who seek for new flavors, healthy and alternative food.
\end{abstract}

Keywords: Punica granatum L. Edible ices. Dairy products. Bromatology.

\footnotetext{
${ }^{1}$ Graduando em Engenharia Agronômica, Univasf, Campus Ciências Agrárias, Petrolina, PE. E-mail para correspondência: souza.coelho.18@gmail.com

${ }^{2}$ Professora Adjunta, DSc em Engenharia Agrícola, Univasf - Campus Ciências Agrárias, Petrolina, PE.

${ }^{3}$ MSc em Engenharia de Alimentos, Universidade Federal de Santa Catarina, Florianópolis - SC

${ }^{4}$ Engenheira Agrônoma, Univasf - Campus Ciências Agrárias, Petrolina, PE

${ }^{5}$ Mestranda em Agronomia -Produção Vegetal, Univasf - Campus Ciências Agrárias, Petrolina, PE.

${ }^{6}$ Engenheiro Agrônomo, Univasf - Campus Ciências Agrárias, Petrolina, PE.
} 


\section{INTRODUÇÃO}

A romãzeira (Punica granatum L.) é uma planta de porte arbustiva, lenhosa e ramificada, pertencente à família botânica Punicaceae, apresenta folhas pequenas, rijas, brilhantes e membranáceas, flores vermelho-alaranjadas dispostas nas extremidades dos ramos, originando frutos esféricos, com muitas sementes angulosas em camadas as quais se acham envolvidas em arilo polposo (LORENZI; SOUZA, 2001; FERREIRA, 2004).

É uma frutífera que apresenta boa aptidão de produção em regiões áridas e semiáridas, sendo mundialmente explorada em função dos inúmeros benefícios funcionais, nutricionais e nutracêuticos (SUMNER et al. 2005).

A cultura da romã é explorada em mais de 100 países do mundo, tendo como principal finalidade o consumo in natura, com aplicações em no campo da medicina moderna (MANICA, 2007), em função do seu histórico medicinal, e por seu elevado potencial antioxidante, devido à presença de compostos fenólicos, os quais são responsáveis pela prevenção de doenças (SALGADO et al. 2012).

O cultivo da romãzeira ocupa cerca de $300 \mathrm{mil} \mathrm{ha} \mathrm{no} \mathrm{mundo,} \mathrm{se} \mathrm{distribuindo} \mathrm{na} \mathrm{Índia,} \mathrm{China,} \mathrm{Irã,}$ Turquia, Estados Unidos da América, Espanha, Egito e Israel, além de serem países que se destacam em termos de desenvolvimento das exportações, pesquisas, produção, desenvolvimento do mercado e novas variedades (QUIROZ, 2009).

No Brasil, a cultura da romã foi introduzida pelos espanhóis, onde encontrou condições amplamente favoráveis para um crescimento vegetativo, florescimento, frutificação e produção de frutos de primeira qualidade (MORENO, 2010).

A variedade de romã 'Wonderful' é uma das mais produzidas no Brasil, e atrativas no mercado internacional, por possuir frutos com arilo de coloração vermelho intenso, de maiores tamanhos e com maior rendimento de suco (OLIVEIRA et al., 2012).

O sorvete é um produto de boa aceitação sensorial, que agrada diversos paladares de diversas faixas etárias, por se tratar de um gelado comestível a base de leite que combina muito bem com o clima tropical do Brasil, e uma ótima perspectiva para seu crescimento industrial e comercial (ALVAREZ et al. 2005).

O consumo per capita anual de sorvetes no Brasil ainda é pouco expressivo quando comparado aos países nórdicos, De acordo com os dados da Associação Brasileira de Indústrias de Sorvetes (ABIA, 2017), o consumo em 2017 esteve na faixa de 5,44 litros de sorvete/ano por habitante, com faturamento do setor acima de $\mathrm{R} \$ 12$ bilhões.

O avanço dos conhecimentos sobre a relação entre alimentação e saúde, bem como os elevados custos da saúde pública e a busca permanente da indústria por inovações têm gerado novos produtos com funções especificas além do conhecido papel nutricional dos alimentos. Pesquisas estão sendo realizadas para identificação e quantificação de novos compostos bioativos e o estabelecimento de bases científicas para a comprovação das alegações de propriedades funcionais dos alimentos como as e seus derivados (SALES, 2008).

Morzelle et al. (2012), avaliaram as propriedades nutricionais, microbiológicas e sensoriais de sorvetes elaborados com frutas exóticas da região do cerrado brasileiro, entre elas, araticum (Annonacrassiflora), pequi (Caryocar brasiliense Camb.), mangaba (Hancorniaspeciosa) e curriola (Pouteriaramiflora), constaram-que orvetes analisados apresentaram significativas características nutricionais e sensoriais, ressaltando sua possível viabilidade comercial.

E um estudo recente realizado por Arruda et al. (2016), foi estudado o uso da polpa de frutos do Cerrado brasileiro araticum e cagaita para desenvolver novos produtos e avaliar a aceitabilidade sensorial por crianças de 7 a 9 anos de idade, entre eles o doce de leite (padrão), com polpa de araticum e com polpa 
de araticum e coco ralado; refresco de cagaita: polpa de cagaita, polpa de cagaita e suco de laranja e polpa de cagaita e suco de cenoura; e uma formulação de geleia de cagaita.

Portanto, o objetivo deste trabalho foi desenvolver uma formulação de sorvete a base de leite, saborizado com polpa de romã 'Wonderful' e avaliar as características físico-químicas do mesmo.

\section{MATERIAL E MÉTODO}

As matérias-primas utilizadas para a elaboração do sorvete foram: leite integral UHT, leite em pó, açúcar cristal, creme de leite, estabilizante e emulsificante, adquiridos no mercado local do município de Petrolina-PE. Os frutos da romã vermelha da variedade 'Wonderful' foram adquiridos na Fazenda Frei Damião (Seridan Agrícola), localizada no município de Casa Nova - BA.

\section{Processamento da romã}

Os frutos foram selecionados manualmente, escolhendo-se os exemplares em estádio de maturação maduro que apresentaram coloração da casca avermelhada, boa integridade física, ausência de fissuras ou manchas e com boa qualidade visual e fitossanitária. Em seguida, lavados em água corrente, sanitizados em solução de hipoclorito de sódio a $50 \mathrm{ppm}$, durante $15 \mathrm{~min}$, enxaguados em água corrente para a retirada do cloro. Para o despolpamento das romãs, os frutos foram partidos ao meio, e foi feita a retirados dos aríolos e sementes para trituração em liquidificador de uso doméstico, em seguida foram peneiradas para a separação do resíduo. A polpa foi acondicionada em sacos de polietileno de baixa densidade e armazenada em freezer $\left(-18 \pm 1^{\circ} \mathrm{C}\right)$.

\section{Análise físico-química da polpa da romã}

A polpa de romã foi avaliada quanto os parâmetros de: $\mathrm{pH}$, sólidos solúveis ( ${ }^{\circ}$ Brix), acidez titulável, e vitamina $\mathrm{C}$.

$\mathrm{O} \mathrm{pH}$ foi medido através do método potenciométrico, com uso de um pHmetro digital de bancada com precisão de 0,01, calibrado com soluções tampões de pH 7,0 e 4,0 respectivamente. O teor de sólidos solúveis foi determinado pelo refratômetro do tipo Abbe, com resultados corrigidos para $20{ }^{\circ} \mathrm{C}$ expressos em ${ }^{\circ}$ Brix. A acidez titulável foi determinada por volumetria ácido-base, empregando como agente titulante a solução de $\mathrm{NaOH}$ a 0,1 mol. $\mathrm{L}^{-1}$ e como indicador fenolftaleína alcoólica a $1 \%$. As análises de pH, teor de sólidos solúveis e acidez titulável foram realizadas de acordo com o as metodologias do Instituto Adolfo Lutz (IAL, 2008). A vitamina C foi determinada por meio de volumetria de óxido redução, empregando a solução de 2,6-diclorofenol-indofenol como agente titulante a 0,02\%, seguindo a metodologia descrita pela AOAC (WILLIANS, 1984), e modificada por Benassi e Antunes (1988).

\section{Elaboração do sorvete}

Para a saborização do sorvete foi elaborada uma calda, através da cocção da polpa de romã junto ao açúcar cristal (sacarose) nas seguintes proporções: 2 partes de polpa para 0,8 de açúcar, até atingir 50 ${ }^{\circ}$ Brix.

O sorvete foi preparado a partir de uma mistura base para gelados comestíveis à base de leite, elaborada da seguinte forma: adição dos ingredientes sólidos misturados (açúcar, leite em pó e emulsificante) ao leite liquido (UHT) e posteriormente a adição de ingredientes líquidos e/ou pastosos misturados (creme de leite e liga neutra) no leite e homogeneização, originando uma calda. Após a mistura e homogeneização a calda foi pasteurizada a $65^{\circ} \mathrm{C}$ por 30 minutos; resfriada a $8{ }^{\circ} \mathrm{C}$; e mantida em maturação a $4^{\circ} \mathrm{C}$ por 12 horas. 
Após a maturação, foi feita a adição do concentrado de romã, e o batimento do sorvete em pressão média de $75 \mathrm{kgf.cm}{ }^{-2}$, com agitação constante para incorporação do ar a mistura, até atingir uma temperatura de $-8{ }^{\circ} \mathrm{C}$, utilizando uma máquina sorveteira industrial modelo PRO 4 - Finamac. Em seguida o produto final (sorvete) foi envasado e acondicionado em embalagens plásticas de polipropileno com capacidade de 5 litros, e armazenadas sob temperatura $-18{ }^{\circ} \mathrm{C}$ para endurecer, em período de 24 horas

A Tabela 1 apresenta o percentual de ingredientes na formulação utilizada para a elaboração do sorvete.

Tabela 1. Formulação utilizada na elaboração do sorvete de romã.

\begin{tabular}{cc}
\hline Ingrediente & Quantidade (\%) \\
\hline Leite Integral & 59,18 \\
Leite em Pó & 9,46 \\
Açúcar cristal & 4,74 \\
Creme de Leite & 2,96 \\
Estabilizante & 0,60 \\
Emulsificante & 0,89 \\
Concentrado de romã & 22,17 \\
\hline
\end{tabular}

\section{Análise físico-química do sorvete de romã}

O sorvete de romã foi avaliado quanto aos parâmetros de: $\mathrm{pH}$, acidez titulável, sólidos totais, umidade, açúcares redutores, açúcares não redutores, açúcares totais, gordura, resíduo mineral, vitamina C, magnésio, zinco, cobre, chumbo, manganês e ferro.

$\mathrm{O} \mathrm{pH}$ foi medido através do método potenciométrico, com uso de um pHmetro digital de bancada com precisão de 0,01 , calibrado com soluções tampões de pH 7,0 e 4,0 respectivamente. A acidez titulável expressa em ácido cítrico foi determinada por volumetria ácido-base, empregando a solução de $\mathrm{NaOH}$ a $0,1 \mathrm{Mol} . \mathrm{L}^{-1}$ como agente titilante e como indicador a solução alcóolica de fenolftaleína alcoólica a $1 \%$. A umidade (\% b.u.) foi determinada por gravimetria, por secagem direta em estufa a $105^{\circ} \mathrm{C}$ até peso constante e calculado o teor de sólidos totais. Os açúcares redutores e não redutores foram determinados por volumetria de oxido-redução, baseando-se na redução do cobre em solução cúprica pelos açúcares. Os açúcares totais foram calculados através da soma dos açúcares redutores e não redutores; a gordura foi determinada por extração com solventes orgânicos. A matéria inorgânica (cinzas ou resíduo mineral), foi determinada através da com incineração da matéria orgânica utilizando uma mufla a $570{ }^{\circ} \mathrm{C}$. Todas estas análises citadas acima foram realizadas de acordo com as metodologias do Instituto Adolfo Lutz (IAL, 2008).

A quantidade de ácido ascórbico (vitamina $\mathrm{C}$ ), foi determinado por meio de volumetria de óxidoredução, empregando a solução de 2,6-diclorofenol-indofenol como agente titulante, conforme o método descrito pela AOAC (WILLIANS, 1984), modificado por Benassi e Antunes (1988).

Para a determinação dos minerais presentes de magnésio $(\mathrm{Mg})$, zinco $(\mathrm{Zn})$, cobre $(\mathrm{Cu})$, ferro $(\mathrm{Fe})$ e manganês no sorvete, seguiu-se a metodologia indicada por Silva (1999), sendo quantificado por meio de espectrofotometria de absorção atômica com atomização eletrotérmica, em equipamento de marca (ETAAS) do modelo ANALYTIKJENA AG (AAS ZEEnit 60), com chama ar/acetileno nas proporções recomendadas pelo fabricante do instrumento para os diferentes elementos. Os resultados foram expressos em $\mathrm{mg} \cdot \mathrm{g}^{-1}$. Todas as análises foram realizadas em triplicatas. 


\section{Tratamento dos dados}

Os resultados obtidos foram submetidos a análise estatística descritiva, através da obtenção dos valores médios e os respectivos coeficientes de variação utilizando o software Microsoft Excel 2010.

\section{RESULTADO E DISCUSSÃO}

Na Tabela 2 encontram-se os valores médios da caracterização físico-química da polpa da romã, com respectivos desvios padrão.

Quanto ao pH da polpa, segundo Gava (2008), classifica-se como um alimento muito ácido, por apresentar valor de $\mathrm{pH}<4,0$. Um alimento muito ácido torna a flora bastante restrita para bactérias láticas e acéticas, bolores e leveduras, o que constitui um fator desfavorável ao crescimento de microrganismos patogênicos. Al-Maiman; Ahmad (2002), encontraram um valor de 3,48, ao avaliarem o fruto da romãzeira vermelha.

Tabela 2. Valores médios dos parâmetros físico-químicos da polpa da romã utilizada na elaboração do sorvete.

\begin{tabular}{ccc}
\hline Parâmetro & Valor \pm Desvio Padrão & CV (\%) \\
\hline $\mathrm{pH}$ & $3,85 \pm 0,03$ & 0,69 \\
Sólidos solúveis $\left({ }^{\circ} \mathrm{Brix}\right)$ & $13,24 \pm 0,14$ & 1,09 \\
Acidez titulável $\left(\mathrm{g}\right.$ de ácido cítrico. $\left.100 \mathrm{~g}^{-1}\right)$ & $0,42 \pm 0,01$ & 1,77 \\
Vitamina $\mathrm{C}\left(\mathrm{mg} .100 \mathrm{~g}^{-1}\right)$ & $26,58 \pm 0,6$ & 1,55 \\
\hline
\end{tabular}

O teor de sólidos solúveis ( ${ }^{\circ}$ Brix) indica a quantidade de sólidos que se encontram dissolvido na água presente nos frutos (CHITARRA; CHITARRA, 2005). A determinação destes sólidos fornece informações relevantes para a agroindústria, a partir destas informações pode-se definir a quantidade correta de matéria-prima e insumos a serem utilizados no processo de fabricação e na elaboração do sorvete (SILVA, 2013).

Quanto maior a quantidade de sólidos solúveis na polpa dos frutos, menor será a quantidade de açúcar adicionada no produto, diminuindo o custo de produção e aumentando a qualidade e rendimento do produto final (ABREU et al., 2009). Al-Maiman e Ahmad (2002) ao avaliarem a quantidade de sólidos solúveis na polpa da romã encontraram um valor de $16,3^{\circ}$ Brix, sendo superior ao encontrado neste estudo.

A acidez constitui um fator de grande importância para o sabor e aroma dos frutos e é atribuída, principalmente, aos ácidos orgânicos dissolvidos nas células, tanto na forma livre como combinada (CHITARRA; CHITARRA, 2005). A presença destes ácidos orgânicos em gelados comestíveis a base de leite favorece a conservação, sendo desnecessária a adição de ácido cítrico, que é comumente utilizado em diversas formulações visando à inibição do crescimento de leveduras (FERREIRA, 2010). Ataíde et al. (2018), ao avaliar a qualidade pós-colheita de frutos de romãzeira comercializados no semiárido pernambucano encontrou uma variação de 2,15 a 2,72 g. $100^{-1}$ de ácido cítrico, valores superiores ao encontrado no presente trabalho

A vitamina $C$ tem papel importante na proteção contra o processo oxidativo. Por ser solúvel em água, age neutralizando ações prejudiciais que ocorrem em meio aquoso, como o sangue (MANCINI; MANCINI FILHO, 2005), sabendo que para adultos a Ingestão Diária Recomendada (IDR) de vitamina C 
é de $45 \mathrm{mg}$ (Brasil, 2005), esta polpa pode ser uma boa fonte de vitamina C, onde o consumo de aproximadamente $170 \mathrm{~mL}$ supre a necessidade do consumo diário de um adulto, quando comparada ao suco da laranja (Citrus sinensis L.) variedade lima que contém cerca de 41,3 mg.100g ${ }^{-1}$ (UNICAMP, 2011) a polpa da romã possui o equivalente a $61,60 \%$ do conteúdo.

$\mathrm{Na}$ Tabela 3, tem-se os valores médios dos parâmetros físico-químicos do sorvete a base de leite saborizado com polpa de romã. Analisando os resultados nota-se que o pH do sorvete $(6,07)$ sofreu influência das demais fontes de sólidos que foram acrescidas ao leite, sendo que a polpa da romã pode ter contribuído significativamente com a redução do pH do leite. De acordo com Mikilita; Cândido (2004), o sorvete apresenta um ótimo meio para o crescimento microbiano, devido ao seu valor nutricional, $\mathrm{pH}$ quase neutro (6-7) e à longa duração do período de armazenamento deverá se dar pela refrigeração. Santana et al. (2003) observaram, em um estudo sobre a qualidade de sorvetes produzidos com vários genótipos de mamão e leite de vaca, valores de $\mathrm{pH}$ variando entre 5,53 e 5,87, valores estes inferiores ao encontrado no presente trabalho.

Em relação a acidez titulável expressa em ácido cítrico, que em sorvetes é um parâmetro influenciado diretamente pela adição de matérias-primas ao leite, e a adição de frutas cítricas. $\mathrm{O}$ valor encontrado é inferior ao relatado por Correia et al. (2008) que obtiveram um teor médio de $0,56 \mathrm{~g} .100 \mathrm{~g}^{-1}$ de ácido cítrico para sorvete de umbu.

Tabela 3. Valores médios dos parâmetros físico-químicos do sorvete a base de leite saborizado com polpa de romã

\begin{tabular}{|c|c|c|}
\hline Parâmetro & Valor \pm Desvio Padrão & $\mathrm{CV}(\%)$ \\
\hline $\mathrm{pH}$ & $6,07 \pm 0,02$ & 0,32 \\
\hline Acidez titulável (g de ácido cítrico. $100 \mathrm{~g}^{-1}$ ) & $0,162 \pm 0,006$ & 3,76 \\
\hline Sólidos totais (\%) & $35,93 \pm 0,04$ & 0,10 \\
\hline Umidade (\% b.u.) & $64,07 \pm 0,04$ & 0,06 \\
\hline Açúcares redutores em glicose $(\%)$ & $4,59 \pm 0,05$ & 1,00 \\
\hline Açúcares não redutores em sacarose (\%) & $8,16 \pm 0,213$ & 2,61 \\
\hline Açúcares totais & $12,7 \pm 0,26$ & 2,03 \\
\hline Gordura (g.100g $\left.\mathrm{g}^{-1}\right)$ & $0,3 \pm 0$ & 0 \\
\hline Cinzas $(\%)$ & $0,843 \pm 0,03$ & 3,42 \\
\hline Vitamina C (mg.100g $\left.\mathrm{g}^{-1}\right)$ & $1,30 \pm 0,30$ & 2,32 \\
\hline Zinco $(\mathrm{Zn})$ total $\left(\mathrm{mg} \cdot \mathrm{g}^{-1}\right)$ & $2,97 \pm 0,01$ & 0,33 \\
\hline Magnésio (Mg) total (mg.g $\left.\mathrm{g}^{-1}\right)$ & $0,30 \pm 0,01$ & 1,95 \\
\hline Cobre $(\mathrm{Cu})$ total $\left(\mathrm{mg} \cdot \mathrm{g}^{-1}\right)$ & ND & - \\
\hline Chumbo $(\mathrm{Pb})$ total $(\mathrm{mg} / \mathrm{g})$ & ND & - \\
\hline Manganês (Mn) total (mg/g) & ND & - \\
\hline Ferro $(\mathrm{Fe})$ total $(\mathrm{mg} / \mathrm{g})$ & ND & - \\
\hline
\end{tabular}

ND - Valor não detectado, abaixo do limite de quantificação estabelecido pela curva, de 0,005 mg/g.

Em relação ao teor de sólidos totais e teor de água (umidade \% b.u.), a formulação desenvolvida enquadra-se em conformidade Legislação Brasileira vigente (BRASIL, 2005a), que preconiza o teor 
mínimo de $26 \%$ de sólidos totais para gelados comestíveis a base de leite e, portanto um teor máximo de $74 \%$ de umidade.

Segundo Soler; Veiga (2001), quanto menor a umidade, maior a concentração de sólidos e isso indica que nesta formulação a quantidade de sólidos utilizados foi elevada. Campidelli et al. (2015), destaca a importância dos sólidos adicionados aos gelados comestíveis a base de leite por atuarem na melhoria da textura e cremosidade do produto elaborado. O valor de umidade e sólidos totais encontrados no presente trabalho foram próximos aos encontrados por Paula et al. (2010) em três formulações de sorvete de leite de cabra adoçado com mel de abelhas africanizadas, variando de 60,78 a 64,19 \% (b.u) e 29,22 e 25,81\%, para umidade e sólidos totais, respectivamente.

Quanto a quantidade de açúcares redutores, não redutores e totais, o sorvete apresentou valores médios de 8,16, 4,59 e 12,75\% respectivamente. Correia et al. (2008) relataram um valor inferior de $3,89 \%$ no que se refere a quantidade de açúcares redutores presentes no sorvete de leite de vaca e polpa de goiaba, já quanto ao teor de açúcares redutores foi relatado um valor de $29,64 \%$, valor este superior ao do presente trabalho.

As fórmulas convencionais de sorvete contêm uma alta concentração de gorduras, que arremete a textura, consistência e sabor do produto. Entretanto a crescente preocupação com a relação entre saúde e alimentação, manutenção do peso saudável e estética corporal, têm contribuído para a conscientização dos consumidores com relação à qualidade da alimentação. Consequentemente, os fabricantes de alimentos estão oferecendo produtos alternativos com características especiais, tais como as variedades "diet" e "light" (CASTRO; FRANCO, 2002; MESICH, 2006). No caso de alimentos para dietas com restrição de gorduras, estes podem conter, no máximo, $0,5 \mathrm{~g}$ de gordura total por $100 \mathrm{~g}$ ou $100 \mathrm{~mL}$ no produto final a ser consumido (BRASIL, 1998).

De acordo com as análises físico-químicas realizadas, o sorvete elaborado apresentou baixo teor de gordura atendendo o limite requerido pela Legislação Brasileira, configurando-se como um alimento alternativo para dietas com restrições de gordura. Correia et al. (2008) de $3,0 \mathrm{~g} .100 \mathrm{~g}^{-1}$ de gorduras totais para de sorvete de leite de vaca com polpa de goiaba.

Quanto ao parâmetro de vitamina C (ácido ascórbico), o sorvete desenvolvido apresentou em seu conteúdo um teor de $1,30 \mathrm{mg} \cdot 100 \mathrm{~g}^{-1}$, valor este inferior ao observado na matéria-prima utilizada. O resultado pode ser justificado a sensibilidade e a degradação deste composto durante o processamento e estocagem por possuir características de uma vitamina hidrossolúvel e termolábil e facilmente oxidada (DANIELI et al., 2009; DANTAS et al., 2010), além disso, na elaboração do sorvete as etapas de pasteurização e incorporação de ar são pontos críticos. Os valores encontrados no presente trabalho foram inferiores ao encontrado por SILVA (2013), que encontrou um teor médio de 1,59 e $5,55 \mathrm{mg} \cdot 100 \mathrm{~g}^{-1}$ ao elaborar formulações de sorvete de leite de cabra saborizado com polpa de umbu e umbu-cajá respectivamente.

Quanto a quantidade de sais minerais (cinzas), têm se os minerais de maior importância presentes no leite que é o cálcio e o fósforo, mas existem ainda outros minerais, como magnésio, flúor, sódio, potássio, cobre, zinco, ferro que representam cerca de 0,6-0,8\% do peso do leite (TRONCO, 2008). Os minerais encontrados na romã segundo Al-Maiman; Ahmad (2002) apresentam cerca de 0,45\%, sendo os principais minerais: ferro, fósforo, cálcio e sódio. O sorvete de romã apresentou conteúdo de cinzas semelhante ao observado por Gonçalves e Eberle (2008) que obtiveram um conteúdo de cinzas para sorvete de umbucajá, de 0,79\%, já Sabatini et al. (2011) relataram valor superior em um estudo sobre a elaboração de sorvete utilizando alfarroba em pó, com conteúdo de cinzas de 3,67\%.

Quanto à quantidade de zinco e magnésio presente no sorvete, sabendo que para adultos a Ingestão Diária Recomendada (IDR) de magnésio é de 260mg e 7mg de Zinco (Brasil, 2005b), conforme os valores 
preconizados, o consumo do sorvete elaborado em torno de $89 \mathrm{~g}$ de sorvete supre a necessidade diária de um adulto quanto o teor de magnésio e em torno de $5 \mathrm{~g}$ supriria a necessidade diária de um adulto quanto o teor de zinco.

\section{CONCLUSÃO}

O sorvete desenvolvido encontra-se de acordo com a Legislação Brasileira vigente quanto ao teor de sólidos totais, apresenta alto valor mineral no que se refere ao zinco e magnésio, e elevado teor de açúcares, além de apresentar-se como um produto ideal para o consumidor que em sua alimentação possui restrição de gorduras.

Não foram detectados teores de cobre, chumbo, manganês e ferro nas amostras. Além disso, a pesquisa de produtos lácteos à base de frutos contribui para a diversificação no mercado, atendendo as necessidades dos consumidores, que buscam por novos sabores, uma alimentação saudável e alternativa.

\section{REFERÊNCIAS}

ABREU, S. P. M.et al.Características físico-químicas de cinco genótipos de maracujazeiro-azedo cultivados no distrito federal. Revista Brasileira de Fruticultura, Jaboticabal, v. 31, n. 2, p. 487-491, 2009.

AL-MAIMAN S. A.; AHMAD, D. Changes in physical and chemical properties during pomegrate (Punica granatum L.) fruit maturation. Food Chemistry, Saudi Arabia, v. 76, n. 4, p. 437-441, 2002.

ALVAREZ, V.B.et al. Physical properties of ice cream containing milk protein concentrates. Journal of Dairy Science, Champaign, v. 88, n. 3, p. 862-871, 2005.

ARRUDA, H. S.et al. Development and sensory evaluation of products containing the Brazilian Savannah fruits araticum (Annona crassiflora Mart.) and cagaita (Eugenia dysenterica Mart.). Brazilian Journal of Food and Technology, Campinas, v. 19, p. e2015105, 2016.

\section{ASSOCIAÇÃO BRASILEIRA DAS INDÚSTRIAS DA ALIMENTAÇÃO. ABIA. 2014 Evolução do mercado Brasileiro de sorvetes Disponível em: < http://www.sicongel.org.br/arquivos/EvolucaodoMercadoBrasileirodeSorvetesMaio2014.pdf> Acesso 1 de junh. de 2015.}

ATAÍDE, E. L. M. A.et al.Qualidade pós-colheita de romã comercializada no semiárido Pernambucano. Agrarian Academy, Goiânia, v. 5, n.9, p. 429-436, 2018.

BENASSI, M. T.; ANTUNES, A. J. A. Comparison of meta-phosphoric and oxalic acids as extractant solutions for the determination of vitamin $\mathrm{C}$ in selected vegetables. Arquivos de Biologia e Tecnologia, Curitiba, v. 31, n. 4, p. 507-513, 1988.

BRASIL, Agência Nacional de Vigilância Sanitária. Resolução n. 266 de 22 de setembro de 2005a. Regulamento técnico para fixação de identidade e qualidade de gelados comestíveis e, preparados para gelados comestíveis, pós para o preparo e bases para gelados comestíveis. Diário Oficial da União, Brasília, 2005a. Disponível em: 〈http://www.anvisa.gov.br/elegis〉. Acesso em: 10 fev. 2019.

BRASIL. Agência Nacional de Vigilância Sanitária - ANVISA. Portaria No 29, de 13 de Janeiro de 1998. Portaria $\mathrm{n}^{\circ}$ 540, de 27 de outubro de 1997. Aprovar o Regulamento Técnico referente a Alimentos para Fins Especiais. Diário Oficial [da] República Federativa do Brasil, Poder Executivo, Brasília, DF, 2815 de outjan. 19987. 
BRASIL. Agência Nacional de Vigilância Sanitária. ANVISA. Ministério da Saúde. Resolução RDC no 269 , de 22 de setembro de 2005. Aprova o regulamento técnico sobre a Ingestão Diária Recomendada (IDR) de proteína, vitaminas e minerais. Diário Ofcial da União, Poder Executivo, Brasília, 2005b. Disponível em: < http://portal.anvisa.gov.br/documents/33916/394219/RDC_269_2005.pdf/2e95553ca482-45c3-bdd1-f96162d607b3>. Acesso em: 10 fev. 2019.

CAMPIDELLI, M. L. L.et al. Efeitos do enriquecimento da semente de chia (Salvia hispanica) nas propriedades do sorvete de mirtilo (Vaccinium myrtillus). Revista Brasileira de Tecnologia Agroindustrial, Ponta Grossa, v. 9, n. 2, p. 1962-1974, 2015.

CASTRO, A.J.P.; FRANCO, L.J. Caracterização do consumo de adoçantes alternativos e produtos dietéticos por indivíduos diabéticos. Arquivos Brasileiros de Endocrinologia e Metabologia, São Paulo, v. 46, n. 3, p. 280-287, 2002.

CHITARRA, M. I. F.; CHITARRA, A. B. Pós-colheita de frutos e hortaliças: fisiologia e manuseio. 2. ed. Lavras: UFLA, 2005. 785 p.

DANIELI, F.et al. Determinação de vitamina $\mathrm{C}$ em amostras de suco de laranja in natura e amostras comerciais de suco de laranja pasteurizado e envasado em embalagem Tetra Pak. Revista do Instituto de Ciência da Saúde, São José do Rio Preto, v.27, n.4, p.361-365, 2009.

DANTAS, R. L.et al.Perfil da qualidade de polpas de fruta comercializadas na cidade de Campina Grande-PB. Revista Verde, v.5, n.5, p.61 - 66, 2010.

FERREIRA, A.B.H. Novo dicionário Aurélio da língua portuguesa. 3.ed. Curitiba: Positivo, 2004. $2120 \mathrm{p}$.

FERREIRA, G. F. Avaliação tecnológica de quatro acessos de umbu cajá (Spondias sp.) do Semiárido da Bahia. 2010. 63p. Dissertação (Mestrado em Ciências Agrárias). Universidade Federal do Recôncavo do Bahia. Cruz das Almas, 2010.

GAVA, A. J.; SILVA, C. A. B.; GAVA J. R. F. Tecnologia de alimentos: princípios e aplicações. São Paulo: Nobel, 2008. 512p.

GONÇALVES, A. A.; EBERLE I. R.; Frozen Yogurt com Bactérias Probióticas. Alimentos e Nutrição, Araquara, v.19, n. 3, p. 291-297, 2008.

IAL - Instituto Adolfo Lutz. Métodos químicos e físicos para análise de alimentos. 4. ed. Normas analíticas do instituto Adolfo Lutz. São Paulo. v.1, 1020p, 2008.

LORENZI, H.; SOUZA, H. M. Plantas ornamentais no Brasil - arbustivas, herbáceas e trepadeiras. 3.ed. Nova Odessa: Plantarum, 2001. 1088p.

MANCINI, D. A. P.; MANCINI-FILHO, J. Prevenção de Reações Oxidativas: antioxidantes nos vegetais de consumo humano. In: DE ANGELIS, R. C. (Ed.) A importância dos alimentos vegetais na proteção da saúde: fisiologia da nutrição protetora e preventiva de enfermidades degenerativas. 2. ed. São Paulo: Atheneu, 2005. cap. 36, p. 206-214.

MANICA, I. Romã (Frutas Nativas e Exóticas). Porto Alegre: Cinco Continentes, 2007; 90p.

MESICH, J. Decisions, decisions, decisions. Candy Industry, New York, v. 171, n. 2, p. 32-33, 2006.

MIKILITA, I. S.; CÂNDIDO, L. M. Fabricação de sorvete: perigos significativos e pontos críticos de controle. Brasil Alimentos, São Paulo, v. 26, n. 4, p. 34-37, 2004.

MORENO P. M. El granado, su problemática y usos. EnIn: I Jornadas nacionales sobre el granado, 7-27 Octubre 2010, Elche, España (CD-ROM). 
MORZELLE, M. C.et al. Caracterização físico-química e sensorial de sorvetes à base de frutos do cerrado. Revista do Instituto de Laticínios Cândido Tostes, Juiz de Fora, v. 67, n. 387, p. 70-78, 2012.

OLIVEIRA, E. M. M.et al. Aplicabilidade da técnica PCR-RAPD para a determinação do perfil genotípico de variedades de romã (Punica granatum). In: II Congresso Brasileiro de Recursos Genéticos, 2., 2012, Belém. Anais. Belém, Sociedade Brasileira de Recurso Genético, 2012. CD-ROM.

PAULA, C. M.et al. Sorvete potencialmente probiótico de leite de cabras, sabor morango, adoçado com açúcar e mel de abelhas africanizadas. Coletânea BITEC. Instituto CENTEC. $8^{a}$ edição 2010, $102 p$.

QUIROZ I., Granado perspectiva y oportunidades de un negocio emergente: antecedentes de mercado. Fundación Chile. 2009.

SALES, R. L.et al. Mapa de preferência de sorvetes ricos em fibras. Ciência e Tecnologia de Alimentos, Campinas, v.28, p.27-31, 2008.

SALGADO, J. M.et al.Increased Antioxidant Content in Juice Enriched with Dried Extract of Pomegranate (Punica granatum) Peel. Plants Food for Human Nutrition, New York, v. 67, n. 1, p. 3943, 2012.

SANTANA, L.; MATSUURA, F.; CARDOSO, R. Genótipos melhorados de mamão (Carica papaya L.) avaliação tecnológica dos frutos na forma de sorvete. Ciência e Tecnologia de Alimentos, Campinas, v. 23, p. 151-155, 2003.

SILVA, A. O. Elaboração de sorvete e iogurte de leite de cabra com frutos do semiárido. 2013. 91 f. Dissertação (Mestreado em Engenharia Agrícola), Universidade Federal de Campina Grande, 2013.

SILVA, F. C. Manual de análises químicas de solos, plantas e fertilizantes. Brasília, DF: Embrapa Comunicação para Transferência de Tecnologia; Rio de Janeiro: Embrapa Solos; Campinas: Embrapa Informática Agropecuária, 1999. 370p.

SOLER, M. P.; VEIGA, P. G. Sorvetes. Campinas: ITAL; CIAL, 2001. 68 p.

SOUZA, J. C. B.et al. Sorvete: composição, processamento e viabilidade da adição de probiótico.

Alimentos e Nutrição, Araraquara, v.21, n.1, p. 155- 165, 2010

SUMNER, M. D.et al. Effects of pomegranate juice consumption on myocardial perfusion in patients with coronary heart disease. Journal of Cardiology, v. 96, p. 810-814, 2005.

TRONCO, V. M. Conceitos Fundamentais. In: Manual para Inspeção da Qualidade do Leite. 3.ed. Santa Maria: Ed. da UFSM, 2008a. p. 11- 38.

UNICAMP. Tabela brasileira de composição de alimentos /NEPA.4. ed. rev. e ampl. Campinas: NEPAUNICAMP, 2011. 161p.

WILLIANS, S. Official Methods of Analysis of the Association of Official Analytical Chemists. 14. ed. Arlington: AOAC, 1984. 1141 p. 